Communication

\title{
Improvements of Electrical Characteristics in Poly-Si Nanowires Thin-Film Transistors with External Connection of a $\mathrm{BiFeO}_{3}$ Capacitor
}

\author{
Tsung-Kuei Kang ${ }^{1, *}$, Yu-Yu Lin ${ }^{1}$, Han-Wen Liu ${ }^{2}{ }^{-}$, Che-Li Lin ${ }^{1}$, Po-Jui Chang ${ }^{2}$, Ming-Cheng Kao ${ }^{3}$ \\ and Hone-Zern Chen ${ }^{3}$ \\ 1 Department of Electronic Engineering, Feng Chia University, Taichung 407, Taiwan; \\ zjwy0507@gmail.com (Y.-Y.L.); jackyjoy551709@gmail.com (C.-L.L.) \\ 2 Department of Electrical Engineering, National Chung Hsing University, Taichung 407, Taiwan; \\ hwliu@dragon.nchu.edu.tw (H.-W.L.); z387253@gmail.com (P.-J.C.) \\ 3 Department of Electrical Engineering, Hsiuping University of Science and Technology, Taichung 407, Taiwan; \\ kmc@hust.edu.tw (M.-C.K.); hzc@hust.edu.tw (H.-Z.C.) \\ * Correspondence: kangtk@fcu.edu.tw; Tel.: +886-42-451-7250 (ext. 4958)
}

check for

updates

Citation: Kang, T.-K.; Lin, Y.-Y.; Liu, H.-W.; Lin, C.-L.; Chang, P.-J.; Kao, M.-C.; Chen, H.-Z.

Improvements of Electrical

Characteristics in Poly-Si Nanowires Thin-Film Transistors with External Connection of $\mathrm{a} \mathrm{BiFeO}_{3}$ Capacitor. Membranes 2021, 11, 758. https:// doi.org/10.3390/membranes11100758

Academic Editor: Francesco Lufrano

Received: 6 September 2021

Accepted: 29 September 2021

Published: 30 September 2021

Publisher's Note: MDPI stays neutral with regard to jurisdictional claims in published maps and institutional affiliations.

Copyright: (c) 2021 by the authors. Licensee MDPI, Basel, Switzerland. This article is an open access article distributed under the terms and conditions of the Creative Commons Attribution (CC BY) license (https:/ / creativecommons.org/licenses/by/ $4.0 /)$.

\begin{abstract}
By a sol-gel method, a $\mathrm{BiFeO}_{3}$ (BFO) capacitor is fabricated and connected with the control thin film transistor (TFT). Compared with a control thin-film transistor, the proposed BFO TFT achieves $56 \%$ drive current enhancement and 7-28\% subthreshold swing (SS) reduction. Moreover, the effect of the proposed $\mathrm{BiFeO}_{3}$ capacitor on $\mathrm{I}_{\mathrm{DS}}-\mathrm{V}_{\mathrm{GS}}$ hysteresis in the BFO TFT is $0.1-0.2 \mathrm{~V}$. Because $\mathrm{dV}_{\mathrm{int}} / \mathrm{dV}_{\mathrm{GS}}>1$ is obtained at a wide range of $\mathrm{V}_{\mathrm{GS}}$, it reveals that the incomplete dipole flipping is a major mechanism to obtain improved SS and a small hysteresis effect in the BFO TFT. Experimental results indicate that sol-gel BFO TFT is a potential candidate for digital application.
\end{abstract}

Keywords: $\mathrm{BiFeO}_{3}$ capacitor; sol-gel method; drive current; hysteresis; subthreshold swing; incomplete dipole flipping

\section{Introduction}

Recently, negative capacitance (NC) transistors have been widely studied, because they are considered to be one of the most promising candidates for low power applications. The NC transistor is first proposed by Salahuddin and Datta. In NC transistors, an embedded ferroelectric film in the gate stack plays a role of voltage amplification [1]. Many studies have been demonstrated transistor integrated with various ferroelectrics, such as HfZrOx [2-7], $\mathrm{PbZrTiO}_{3}[8,9], \mathrm{PVDF}[10,11]$, and $\mathrm{BiFeO}_{3}$ (BFO) [12]. NC transistors are expected to be applied for logic switching, which requires hysteresis-free characteristics. Generally, the phenomena of clockwise hysteresis show their NC effect. Some studies reveal that a complete dipole flipping in ferroelectric can obtain a large hysteresis, but an incomplete dipole flipping in ferroelectric can obtain a small hysteresis [13-15]. BFO is a single phase multiferroic material with a rhombohedrally distorted perovskite with polar space group R3c at room temperature [16]. Although BFO is a very good ferroelectric material, it is still not widely used in negative capacitance transistors. In reference [12], although BFO negative capacitance transistors can achieve a very low subthreshold swing (SS) from 8.5 to $50 \mathrm{mV}$ / decade, the effect of BFO capacitor on the hysteresis is about 4-5 V. Therefore, as far as digital applications are concerned, more studies are needed for BFO negative capacitance transistors. In this paper, $\mathrm{BFO}$ thin film on $\mathrm{Pt}$ will be fabricated by a low-cost sol-gel method [17] and the Poly-Si nanowire junctionless thin film transistor (TFT) externally connected to the BFO capacitor will be investigated. Interestingly, our results reveal that the incomplete dipole flipping in the BFO capacitor plays a major role to obtain a small hysteresis effect in the proposed BFO TFT device. 


\section{Devices Fabrication}

A 100-nm-thick in-situ phosphorus-doped $\left(\mathrm{N}^{+}\right)$Poly-Si was deposited on oxidized silicon wafer by low-pressure chemical vapor deposition (LPCVD). The 100-nm-thick Poly-Si was then patterned, using partial etching to form one 50-nm-thick Poly-Si strip, as shown in Figure 1a. Then, a 20-nm-thick $\mathrm{Si}_{3} \mathrm{~N}_{4}$ film was deposited by LPCVD, as shown in Figure 1b. Next, a 15-nm-thick N+ Poly-Si was deposited by LPCVD at $560{ }^{\circ} \mathrm{C}$ and then annealed at $600{ }^{\circ} \mathrm{C}$ for 10 hours, which recrystallized it into Poly-Si through solid-phase crystallization. Then, using standard I-line lithography, the photoresists on the source/drain (S/D) pads were patterned to overlap on the two edges of the raised strip. After that, a plasma etcher was used to remove the $\mathrm{N}^{+}$Poly-Si, while the spacer $\mathrm{Si}$ channels were formed on the sidewall of each L-type $\mathrm{Si}_{3} \mathrm{~N}_{4}$ film, in situ, and naturally connected to the S/D pads, as shown in Figure 1c. Next, S/D-pad photoresists were removed and 5-nm-thick atomic layer deposition (ALD). $\mathrm{Al}_{2} \mathrm{O}_{3}$ and 100-nm-thick TiN were deposited by sputtering system as the gate oxide and the gate electrode, as shown in Figure 1d. The schematic cross-sectional channel and its TEM image were shown in Figure 1e,f. In this paper, the main purpose is to study the influence of $\mathrm{BiFeO}_{3}(\mathrm{BFO})$ capacitor on the characteristics of transistors. Therefore, the process of control transistors used in the paper is not optimized.

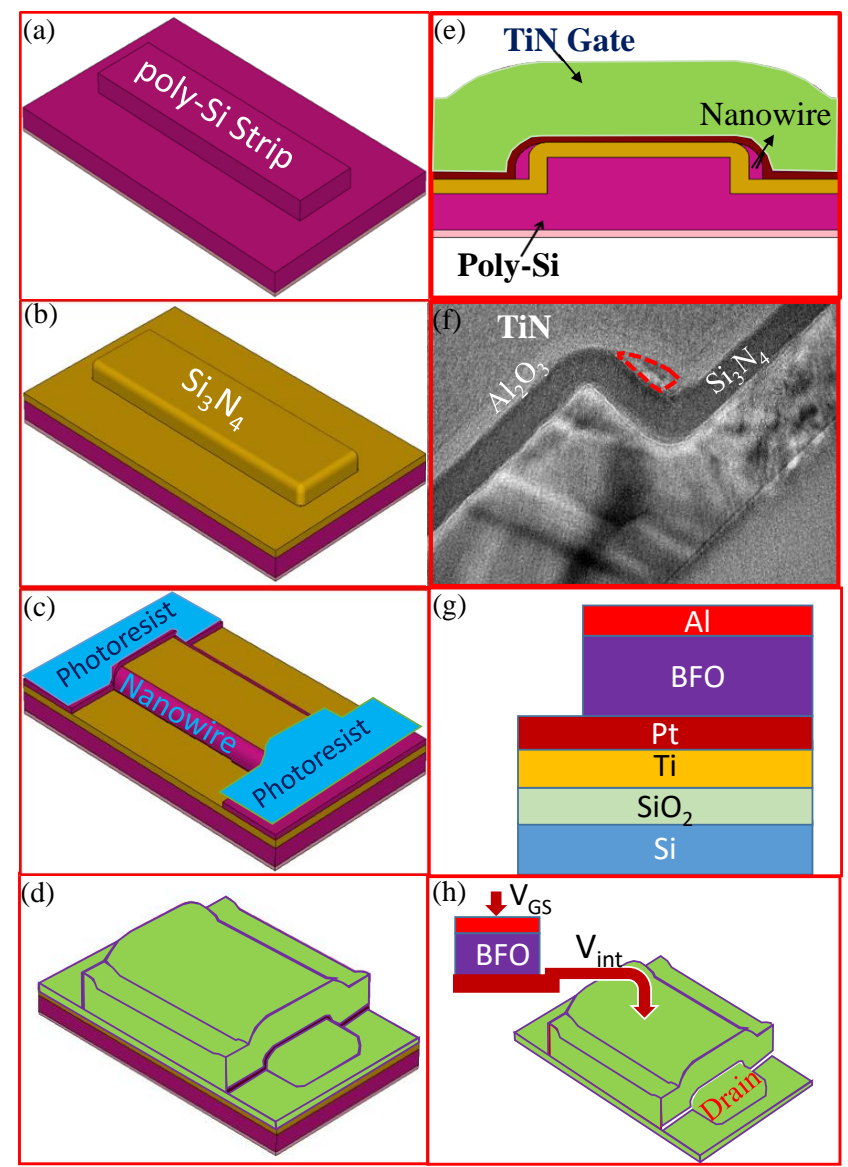

Figure 1. Key fabrication steps for the control TFT and BFO capacitor. (a) $\mathrm{N}^{+}$Poly-Si layer deposition and strip patterning, (b) $\mathrm{Si}_{3} \mathrm{~N}_{4}$ deposition, (c) $\mathrm{N}^{+}$Poly-Si layer deposition, $\mathrm{N}^{+}$Poly-Si NW channels and source/drain were Figure 2. (d) $\mathrm{O}_{3}$ gate oxide and TiN deposition, then gate patterning, (e) the cross-sectional transistor with TiN gate, (f) the cross-sectional TEM image, where the red line indicates the $\mathrm{Si}$ channel. Its peripheries are $9.4 \mathrm{~nm}, 24 \mathrm{~nm}$, and $35 \mathrm{~nm}$, respectively. Due to 5-nm-thick $\mathrm{Al}_{2} \mathrm{O}_{3}$, the effective width (Weff)/channel of TiN gate is about 30nm in control TFT. (g) Schematic diagram of BFO capacitor. (h) A wire is connected to the BFO capacitor and a control transistor where it can be measured. 

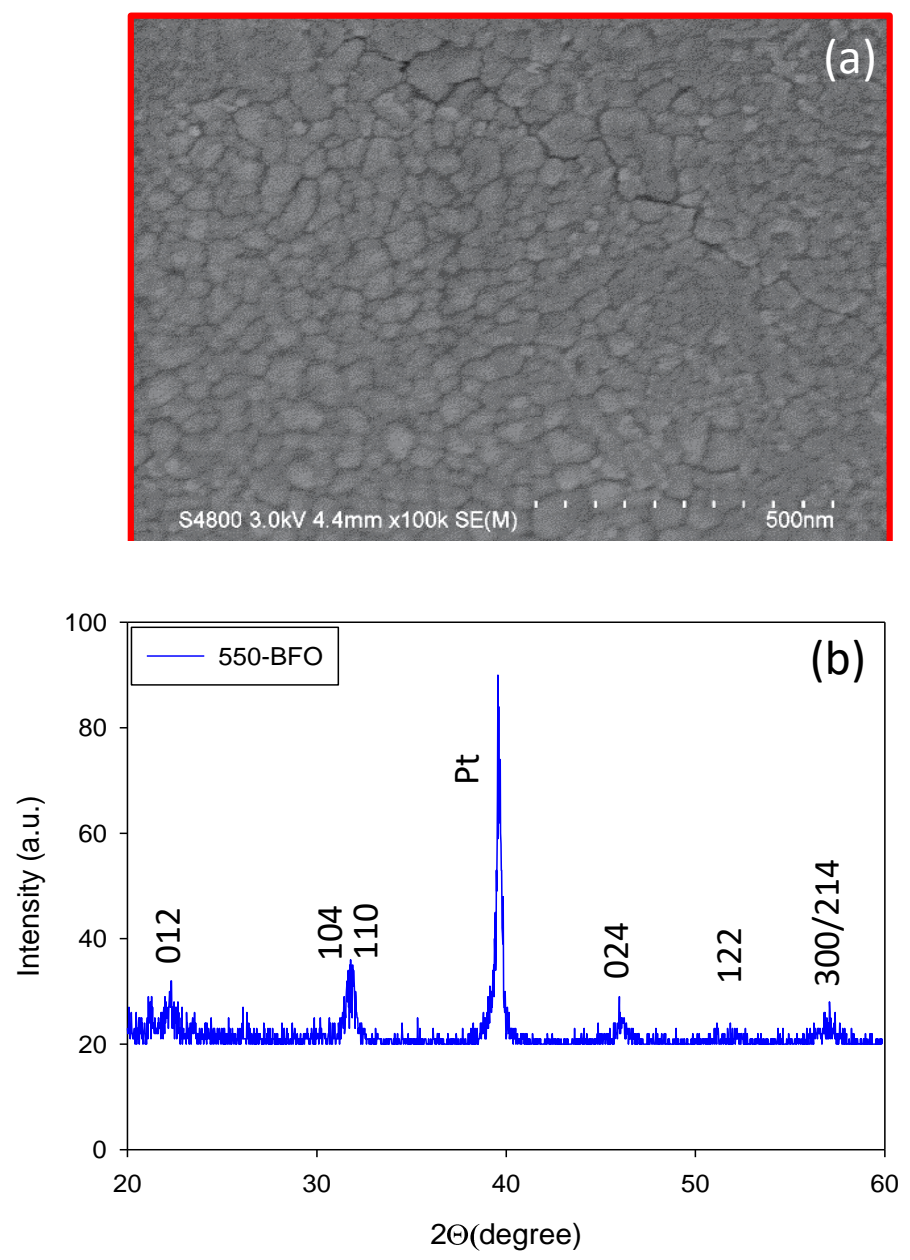

Figure 2. (a) SEM image of BFO film annealed at $550{ }^{\circ} \mathrm{C}$. (b) XRD pattern of BFO film annealed at $550{ }^{\circ} \mathrm{C}$.

For $\mathrm{BiFeO}_{3}$ capacitors, BFO thin film was fabricated on $\mathrm{Pt} / \mathrm{Ti} / \mathrm{SiO}_{2} / \mathrm{Si}$ by a sol-gel method. Bismuth (III) acetate $\left[\mathrm{Bi}\left(\mathrm{OOCCH}_{3}\right)_{3}\right]$ and $\mathrm{Iron}(\mathrm{III})$ 2,4-pentanedionate $\left[\mathrm{C}_{15} \mathrm{H}_{21} \mathrm{FeO}_{6}\right]$ were used as raw materials. These starting materials were first dissolved in propionic acid and 2-methoxyethanol with Bi excess $5 \%$. The solution was then stirred at $80{ }^{\circ} \mathrm{C}$ for $4 \mathrm{~h}$ to obtain a uniform sol solution, and was subsequently coated in $\mathrm{Pt} / \mathrm{Ti} / \mathrm{SiO}_{2} / \mathrm{Si}$ substrate with $2500 \mathrm{rpm}$ for $30 \mathrm{~s}$ and dried at $300{ }^{\circ} \mathrm{C}$ for $2 \mathrm{~min}$. This step was repeated 10 times to obtain the final BFO films $(\sim 300 \mathrm{~nm})$. The BFO film was annealed at $550{ }^{\circ} \mathrm{C}$ for 30 s and called 550-BFO. Finally, Al were deposited by sputtering as with the top gate, as shown in Figure 1g. A wire was connected to the 550-BFO capacitor and control TFT, as shown in Figure 1h. All upper electrodes were circular, and a BFO capacitor with a radius of $170 \mu \mathrm{m}$ was used in the study of the NC effect in the resistive-capacitive (RC) circuit, and the BFO capacitor with a radius of $28 \mathrm{um}$ was connected in series with the control transistor. The size of the control TFT is Weff $=30 \mathrm{~nm} \times 2 / \mathrm{L}=5 \mu \mathrm{m}$ in the proposed 550-BFO TFT.

\section{Results and Discussion}

For BFO film, the grain structure of the film was detected using a scanning electron microscope (SEM), as shown in Figure 2a. The 550-BFO film shows relatively obvious grains. It reveals that the $\mathrm{BFO}$ film annealed at $550{ }^{\circ} \mathrm{C}$ is well crystallized. XRD patterns of the BFO film annealed at $550{ }^{\circ} \mathrm{C}$ is shown in Figure $2 \mathrm{~b}$ and the (012), (110), (104), (024), (122), (300), and (214) diffraction peaks can be observed. The XRD peaks are quite similar to those of standard diffraction patterns of pure BFO on the joint committee on powder diffraction standards (JCPDS \#71-2494) card. This indicates the formation of pure BFO 
phase, good crystallization, and rhombohedrally-distorted perovskite crystal structure with space group R3c [18]. According to the previous study, it reveals that the proposed 550-BFO film has good ferroelectric properties [18].

To study the NC effect, we created an RC circuit diagram of the experimental setup where the 550-BFO capacitor is connected in series with an external resistor Rs $=500 \Omega$, as shown in Figure 3a. An AC voltage pulse sequence of $\mathrm{Vs}:-5 \mathrm{~V} \rightarrow+5 \mathrm{~V} \rightarrow-5 \mathrm{~V}$ was applied as input and the voltage $\left(\mathrm{V}_{\mathrm{F}}\right)$ across the $\mathrm{BFO}$ capacitor was recorded by an oscilloscope. Figure $3 \mathrm{~b}$ shows the transient response of $\mathrm{V}_{\mathrm{F}}$ from $-5 \mathrm{~V}$ to $+5 \mathrm{~V}$ and from $+5 \mathrm{~V}$ to $-5 \mathrm{~V}$ for the 550-BFO capacitor. In Figure 3b, the spike behavior can be understood in the following sequence: initial rise, initial ferroelectric response, and final ferroelectric response. According to reference [12], the NC time is defined the elapsed time from the highest value (or lowest value) to the lowest value (or highest value) of $V_{F}$ in "initial ferroelectric response" and a longer NC time shows a longer charge compensation time after domain switching. Obviously, for the positive domain switching, the NC time is $0.160 \mu \mathrm{s}$ and $0.136 \mu$ s for the negative domain switching. Therefore, whether with forward- or reverse sweeping, it is expected that the characteristics of 550-BFO TFT will be improved over the control TFT.
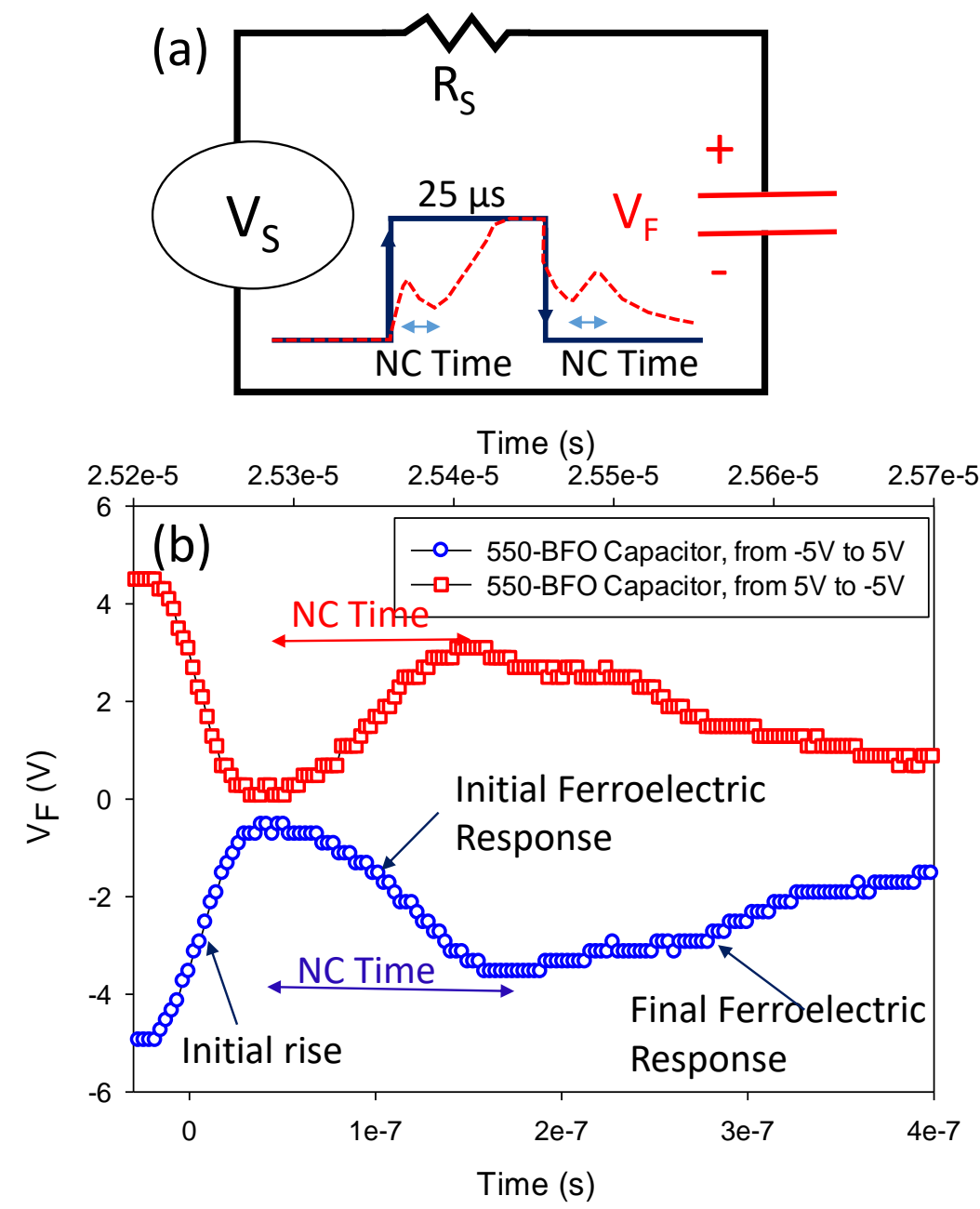

Figure 3. (a) Schematic diagram of experimental setup where the BFO capacitor is connected in series with a resistor ( $\mathrm{RC}$ circuit). The pulse time is $25 \mu \mathrm{s}$. In the zoom, the solid line represents the input Vs signal and the dotted line represents the output voltage of the BFO capacitor. (b) Transient response of $\mathrm{V}_{\mathrm{F}}$ for BFO capacitor. The NC time is $0.160 \mu$ s from $-5 \mathrm{~V}$ to $5 \mathrm{~V}$ and $0.136 \mu$ s from $5 \mathrm{~V}$ to $-5 \mathrm{~V}$. 
The $\mathrm{I}_{\mathrm{DS}}-\mathrm{V}_{\mathrm{GS}}$ transfer characteristics at $\mathrm{V}_{\mathrm{DS}}$ of $0.1 \mathrm{~V}$ and $2 \mathrm{~V}$ for control TFT and 550BFO TFT are shown in Figure $4 \mathrm{~b}$, respectively. The $\mathrm{V}_{\mathrm{TH}}$ is defined as the gate voltage that is required to obtain a normalized drain current of $\mathrm{I}_{\mathrm{DS}}=\left(\mathrm{W}_{\mathrm{eff}} / \mathrm{L}\right) \times 10^{-8}$ A. For $550-\mathrm{BFO}$ TFT, the hysteresis from $0.59 \mathrm{~V}$ to $0.45 \mathrm{~V}$ at $\mathrm{V}_{\mathrm{DS}}$ of $0.1 \mathrm{~V}$ is observed, as shown in Figure $4 \mathrm{a}$. At $\mathrm{V}_{\mathrm{DS}}$ of $2 \mathrm{~V}$, the hysteresis from $0.6 \mathrm{~V}$ to $0.4 \mathrm{~V}$ is observed, as shown in Figure $4 \mathrm{~b}$. From the hysteresis curves, the effect of the $550-\mathrm{BFO}$ capacitor on hysteresis is about $0.14 \mathrm{~V}$ and $0.2 \mathrm{~V}$ at $0.1 \mathrm{~V}$ and $\mathrm{V}_{\mathrm{DS}}$ of $2 \mathrm{~V}$, respectively. For 550-BFO TFT, no matter at $\mathrm{V}_{\mathrm{DS}}$ of $0.1 \mathrm{~V}$ or $2 \mathrm{~V}$, the $\mathrm{ON}$ current $\left(\mathrm{I}_{\mathrm{ON}}\right)$ at $\mathrm{V}_{\mathrm{GS}}$ of $3 \mathrm{~V}$ shows $56 \%$ enhancement over control TFT.
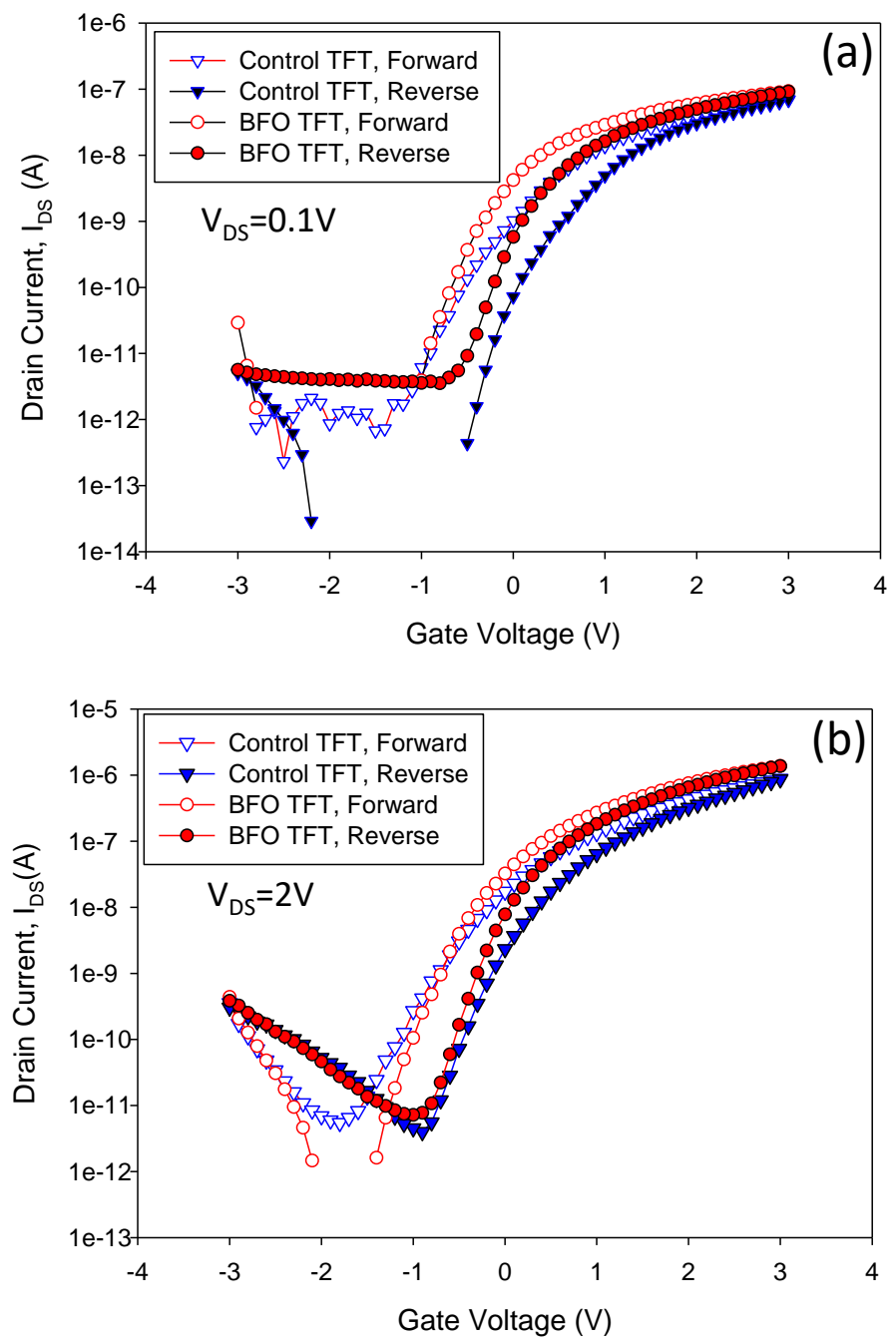

Figure 4. (a) $\mathrm{I}_{\mathrm{DS}}-\mathrm{V}_{\mathrm{GS}}$ transfer characteristics at $\mathrm{V}_{\mathrm{DS}}$ of $0.1 \mathrm{~V}$ for control TFT $(\mathrm{L}=5 \mu \mathrm{m}$, Weff $=60 \mathrm{~nm})$ and 550-BFO TFT. (b) $\mathrm{I}_{\mathrm{DS}}-\mathrm{V}_{\mathrm{GS}}$ transfer characteristics at $\mathrm{V}_{\mathrm{DS}}$ of $2 \mathrm{~V}$ for control TFT and 550-BFO TFT.

Figure $5 \mathrm{a}, \mathrm{b}$ shows the point $\mathrm{SS}$ versus $\mathrm{I}_{\mathrm{DS}}$ curves for control TFT and 550-BFO TFT. Compared with control TFT, no matter forward sweeping or reverse sweeping, 550-BFO TFT show improved SS characteristics at $\mathrm{V}_{\mathrm{DS}}$ of $0.1 \mathrm{~V}$ or $2 \mathrm{~V}$ over control TFT. In the IDS range of $1 \times 10^{-8}$ to $1 \times 10^{-11} \mathrm{~A}$, the average SS value is reduced by $28 \%$ for forward sweeping and $7 \%$ for reverse sweeping. The SS data is consistent with the trend of NC time of positive and negative domain switching. Based on the assumption that the $\mathrm{I}_{\mathrm{DS}}$ of 550-BFO TFT is the same as the control TFT, the extracted $V_{\text {int }}-V_{G S}$ curve at $V_{D S}$ of $0.1 \mathrm{~V}$ can be obtained [15]. $\mathrm{dV}_{\mathrm{int}} / \mathrm{dV}_{\mathrm{GS}}$ versus $\mathrm{V}_{\mathrm{GS}}$ can be calculated, as shown in Figure 5c. It is found that $\mathrm{dV}_{\mathrm{int}} / \mathrm{dV}_{\mathrm{GS}}>1$ is obtained at a wide range of $\mathrm{V}_{\mathrm{GS}}$, leading to the improved SS over control TFT in the whole measuring range of $\mathrm{I}_{\mathrm{DS}}$ in 550-BFO TFT. The previous study reported that the mechanism underlying near $\mathrm{I}_{\mathrm{DS}}-\mathrm{V}_{\mathrm{GS}}$ hysteresis-free transistor is 
incomplete dipoles flipping, rather than complete dipoles switching in the transistor with a large $\mathrm{I}_{\mathrm{DS}}-\mathrm{V}_{\mathrm{GS}}$ hysteresis [15]. Therefore, the incomplete dipole flipping plays a major role to obtain improved SS and a small hysteresis effect in the proposed 550-BFO TFT. According to the data and discussion mentioned above, it reveals that sol-gel BFO TFT is a potential candidate for digital application.
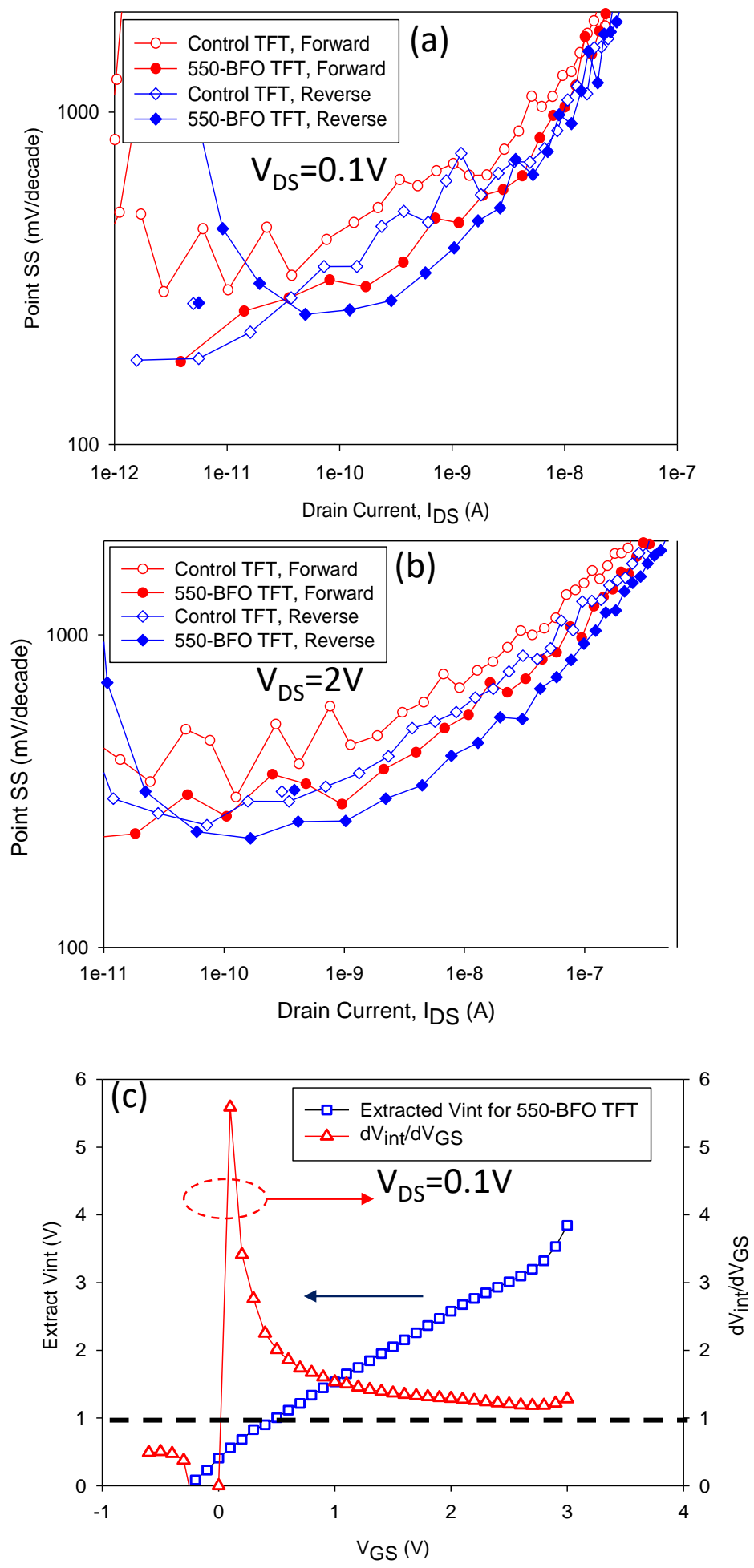

Figure 5. Point SS versus $\mathrm{I}_{\mathrm{DS}}$ curves for (a) control TFT $(\mathrm{L}=5 \mu \mathrm{m}$, Weff $=60 \mathrm{~nm})$ and 550-BFO TFT at $V_{D S}$ of $0.1 \mathrm{~V}$ and (b) at $V_{\mathrm{DS}}$ of $2 \mathrm{~V}$. (c) Extracted Vint and $d V i n t / d V_{G S}$ versus $V_{G S}$ at $V_{D S}$ of $0.1 \mathrm{~V}$. The position of $V_{G S}$ and $V_{\text {int }}$ are marked in Figure $1 \mathrm{~h}$. 


\section{Conclusions}

The proposed BFO TFT shows improved characteristics of $\mathrm{I}_{\mathrm{ON}}$ increased by $56 \%$ and SS reduced by $7-28 \%$, because the sol gel BFO film show good crystallization, ferroelectric property, and a long enough NC time. Based on the extracted $V_{\text {int }}-V_{G S}$ curve, $\mathrm{dV}_{\mathrm{int}} / \mathrm{dV}_{\mathrm{GS}}>1$ is obtained at a wide range of $\mathrm{V}_{\mathrm{GS}}$. Obviously, the incomplete dipole flipping plays a major role in the proposed BFO TFT. Therefore, the effect of the proposed $\mathrm{BFO}$ capacitor on $\mathrm{I}_{\mathrm{DS}}-\mathrm{V}_{\mathrm{GS}}$ hysteresis in the BFO TFT is small. It reveals that the proposed BFO TFT is a potential candidate for digital application.

Author Contributions: Conceptualization, T.-K.K.; formal analysis, T.-K.K., Y.-Y.L., C.-L.L. and P.-J.C.; methodology, T.-K.K., M.-C.K. and H.-Z.C.; resources, T.-K.K., M.-C.K. and H.-Z.C.; writing-original draft, T.-K.K. and H.-W.L.; writing—review and editing, T.-K.K., H.-W.L. and M.-C.K. All authors have read and agreed to the published version of the manuscript.

Funding: This research was funded by the Ministry of Science and Technology of Taiwan (grant MOST no. MOST.108-2221-E-035-040).

Institutional Review Board Statement: Not applicable.

Informed Consent Statement: Not applicable.

Data Availability Statement: Not applicable.

Conflicts of Interest: The authors declare no conflict of interest.

\section{References}

1. Salahuddin, S.; Datta, S. Use of negative capacitance to provide voltage amplification for low power nanoscale devices. Nano Lett. 2008, 8, 405-410. [CrossRef] [PubMed]

2. Li, K.S.; Chen, P.G.; Lai, T.Y.; Lin, C.H.; Cheng, C.C.; Chen, C.C.; Wei, Y.J.; Hou, Y.F.; Liao, M.H.; Lee, M.H.; et al. Sub-60mV-swing negative-capacitance FinFET without hysteresis. In Proceedings of the 2015 IEEE International Electron Devices Meeting (IEDM), Washington, DC, USA, 7-9 December 2015; pp. 620-623.

3. Lee, M.H.; Wei, Y.-T.; Chu, K.-Y.; Huang, J.-J; Chen, C.-W.; Cheng, C.-C.; Chen, M.-J.; Lee, H.-Y.; Chen, Y.-S.; Lee, L.-H.; et al. Steep slope and near non-hysteresis of FETs with antiferroelectric-like HfZrO for low-power electronics. IEEE Electron Device Lett. 2015, 36, 294-296. [CrossRef]

4. Cheng, C.H.; Chin, A. Low-voltage steep turn-on pMOSFET using ferroelectric high- $\mathrm{k}$ gate dielectric. IEEE Electron Device Lett. 2014, 35, 274-276. [CrossRef]

5. Lee, M.H.; Chen, P.-G.; Liu, C.; Chu, K.-Y.; Cheng, C.-C.; Xie, M.-J.; Liu, S.-N.; Lee, J.-W.; Huang, S.-J.; Liao, M.-H.; et al. Prospects for ferroelectric HfZrOx FETs with experimentally CET $=0.98 \mathrm{~nm}$, SSfor $=42 \mathrm{mV} / \mathrm{dec}$, SSrev $=28 \mathrm{mV} / \mathrm{dec}$, switch-OFF $<0.2 \mathrm{~V}$, and hysteresis-free strategies. In Proceedings of the 2015 IEEE International Electron Devices Meeting (IEDM), Washington, DC, USA, 7-9 December 2015; pp. 616-619.

6. Zhou, J.; Han, G.; Li, Q.; Peng, Y.; Lu, X.; Zhang, C.; Zhang, J.; Sun, Q.-Q.; Zhang, D.W.; Hao, Y. Ferroelectric HfZrOx Ge and GeSn pMOSFETs with sub-60 mV/decade subthreshold swing, negligible hysteresis, and improved IDs. In Proceedings of the 2016 IEEE International Electron Devices Meeting (IEDM), San Francisco, CA, USA, 3-7 December 2016; pp. 310-313.

7. Zhou, J.; Han, G.; Peng, Y.; Liu, Y.; Zhang, J.; Sun, Q.-Q.; Zhang, D.W.; Hao, Y. Ferroelectric negative capacitance GeSn PFETs with sub-20 mV/decade subthreshold swing. IEEE Electron Device Lett. 2017, 38, 1157-1160. [CrossRef]

8. Dasgupta, S.; Rajashekhar, A.; Majumdar, K.; Agrawal, N.; Razavieh, A.; Trolier-Mckinstry, S.; Datta, S. Sub-kT/q switching in strong inversion in $\mathrm{PbZr}_{0.52} \mathrm{Ti}_{0.48} \mathrm{O}_{3}$ gated negative capacitance FETs. IEEE J. Explor. Solid-State Comput. Devices Circuits 2015, 1, 43-48. [CrossRef]

9. Bakaul, S.R.; Serrao, C.R.; Lee, M.; Yeung, C.W.; Sarker, A.; Hsu, S.-L.; Yadav, A.; Dedon, L.; You, L.; Khan, A.I.; et al. Single crystal functional oxides on silicon. Nat. Commun. 2016, 7, 10547. [CrossRef] [PubMed]

10. Rusu, A.; Salvatore, G.A.; Jiménez, D.; Ionescu, A.M. Metal ferroelectric-meta-oxide-semiconductor field effect transistor with sub- $60 \mathrm{mV} /$ decade subthreshold swing and internal voltage amplification. In Proceedings of the 2010 International Electron Devices Meeting, San Francisco, CA, USA, 6-8 December 2010; pp. 395-398.

11. Jo, J.; Shin, C. Negative capacitance field effect transistor with hysteresis-free sub-60-mV/decade switching. IEEE Electron Device Lett. 2016, 37, 245-248. [CrossRef]

12. Khan, A.I.; Chatterjee, K.; Duarte, J.P.; Lu, Z.; Sachid, A.; Khandelwal, S.; Ramesh, R.; Hu, C.; Salahuddin, S. Negative capacitance in short-channel FinFETs externally connected to an epitaxial ferroelectric capacitor. IEEE Electron Device Lett. 2016, 37, 111-114. [CrossRef]

13. Jia, C.-L.; Urban, K.W.; Alexe, M.; Hesse, D.; Vrejoiu, I. Direct observation of continuous electric dipole rotation in flux-closure domains in ferroelectric $\mathrm{Pb}(\mathrm{Zr}, \mathrm{Ti}) \mathrm{O}_{3}$. Science 2011, 331, 1420-1433. [CrossRef] [PubMed] 
14. Naumov, I.; Bratkovsky, A.M. Unusual polarization patterns in flat epitaxial ferroelectric nanoparticles. Phys. Rev. Lett. 2008, 10, 107601. [CrossRef] [PubMed]

15. Zhou, J.; Han, G.; Xu, N.; Li, J.; Peng, Y.; Liu, Y.; Zhang, J.; Sun, Q.Q.; Zhang, D.W.; Hao, Y. Incomplete Dipole Flipping Produced Near Hystersis-Free Negative Capacitance Transistor. IEEE Electron Device Lett. 2019, 40, 329-332. [CrossRef]

16. Quan, Z.C.; Hu, H.; Xu, S.; Liu, W.; Fang, G.; Li, M.; Zhao, X. Surface chemical bonding states and ferroelectricity of Ce-doped $\mathrm{BiFeO}_{3}$ thin films prepared by sol-gel process. J. Sol-Gel Sci. Technol. 2008, 48, 261-266. [CrossRef]

17. Wang, D.; Wang, M.; Liu, F.; Cui, Y.; Zhao, Q.; Sun, H.; Jin, H.; Cao, M. Sol-gel synthesis of Nd-doped BiFeO 3 multiferroic and its characterization. Ceram. Int. 2015, 41, 8768-8772. [CrossRef]

18. Anjum, T.A.; Naveed-Ul-Haq, M.; Hussain, S.; Rafique, M. Analyses of structure, electronic and multiferroic properties of $\mathrm{Bi}_{1-\mathrm{x}} \mathrm{Nd}_{\mathrm{x}} \mathrm{FeO}_{3}(\mathrm{x}=0,0.05,0.10,0.15,0.20,0.25)$ system. J. Alloy. Compd. 2020, 820, 153095. [CrossRef] 